\title{
FITOSSANIDADE
}

\section{EFEITOS DO NÍVEL DE INÓCULO DE MELOIDOGYNE INCOGNITA EM ALGODOEIRO ${ }^{(1)}$}

\author{
MARLUCI MUNDIN ABRÃO ${ }^{(2,3)} ;$ PAULO MAZZAFERA ${ }^{(2,4)}$
}

\section{RESUMO}

Pesquisas acerca da fisiologia de plantas em resposta ao ataque de nematóides normalmente são feitas com doses altas de inóculo, quer sejam ovos ou juvenis de segundo estágio. Diferentemente, as avaliações da resistência de plantas a nematóides em programas de melhoramento são realizadas com doses bastante inferiores. Neste estudo acompanhou-se a variação de alguns parâmetros fisiológicos em algodão, em resposta à aplicação de baixas doses de inóculo de Meloidogyne incognita raça 3. Duas cultivares foram utilizadas, Acala e IAC-20, respectivamente suscetível e moderadamente resistente. Plântulas com duas folhas receberam 500 ou 5.000 ovos e, 90 dias depois, foram comparadas a plantas que não receberam o inóculo, quanto à massa da parte aérea e raízes, fotossíntese, atividade da enzima redutase do nitrato e teores de clorofila e açúcares solúveis. Aos 90 dias algumas plantas também foram submetidas à deficiência hídrica e o potencial da água determinado nas folhas. O maior nível de inóculo levou à redução da parte aérea (massa de folhas) em 'Acala'. Com 500 ovos parece ter ocorrido um estímulo em ambas as cultivares, uma vez que houve tendência de maior crescimento da parte aérea. Em 'Acala' houve maior crescimento de raiz com o aumento do inóculo, provavelmente devido à emissão de raízes secundárias nos pontos de penetração do nematóide e também pela formação de galhas. Houve aumento dos teores de clorofila e de açúcares solúveis, bem como da fotossíntese, com o aumento do inóculo. Discute-se se tal ocorrência deve-se à maior demanda de fotoassimilados para suportar o crescimento de raízes, em 'Acala'. Em IAC-20 esse fato estaria ligado aos mecanismos de defesa induzidos pelo ataque do nematóide. Após o estresse hídrico o potencial da água diminuiu em 'IAC-20' e aumentou na 'Acala', com o aumento do inóculo. A elevação do potencial da água, nesta última cultivar, poderia estar ligada ao crescimento das raízes e, principalmente, à emissão de novas raízes secundárias, ao passo que a resposta em 'IAC-20' seria a previsível, ou seja, de deficiência hídrica.

Palavras-chave: algodão, Gossypium hirsutum, nematóide, Meloidogyne incognita, alterações fisiológicas, nível de inóculo.

\section{ABSTRACT \\ EFFECTS OF LOW INOCULUM LEVEL OF MELOIDOGYNE INCOGNITA ON COTTON PLANTS}

Investigations on physiological responses of plants to nematode are usually carried out with plants inoculated with high number of eggs or second-stage juveniles. On the other hand, resistance against nematodes in plant breeding programs is evaluated with low number of inoculum. The aim of this research was to study some physiological responses of cotton plants inoculated with low inoculum levels of Meloidogyne incognita race 3. Two cultivars were used, Acala and IAC-20, susceptible and moderately resistant hosts respectively. Seedlings with 500 or 5,000 eggs were compared with control plants at 90 days post inoculation. The following aspects were assessed: shoot and root masses,

(1) Recebido para publicação em 18 de abril de 2000 e aceito em 9 de janeiro de 2001.

(2) Departamento de Fisiologia Vegetal, Instituto de Biologia, Universidade Estadual de Campinas (UNICAMP), Caixa Postal 6.109, 13083-970 Campinas (SP). E-mail: pmazza@obelix.unicamp.br

$\left({ }^{3}\right)$ Com bolsa de mestrado do CNPq.

$\left({ }^{4}\right)$ Com bolsa de produtividade em pesquisa do CNPq. 
photosynthesis, activity of the enzyme nitrate reductase, and chlorophyll and soluble sugar contents. At 90 days a water stress was imposed to some plants and the leaf water potentials determined. At 5,000 eggs, 'Acala' had a shoot reduction (leafmass). With 500 eggs, there was an estimulation of shoot growth in both cultivars, as revealed by a shootmass increase There was a clear increase on root growth of 'Acala' which was directly related to the inoculum levels. This response was probably caused by emission of new secondary roots and nematode galls formation. Chlorophyll and sugar content, and photosynthesis increased with the increase of inoculum levels, suggesting a response to support root growth in 'Acala'. In 'IAC-20' these higher values would be related with the energy demanded by defense mechanisms against the nematode. The imposed water stress caused a decrease on leaf water potential in 'IAC-20', but an increase in 'Acala' with increasing inoculum levels. The observed increase in the later cultivar might be related with the root growth, mainly due to emission of new secondary roots, while 'IAC 20' water stress response, would be considered as a pattern.

Key words: cotton, Gossypium hirsutum, nematode, Meloidogyne incognita, physiological effects, inoculum level.

\section{INTRODUÇÃO}

Os nematóides formadores de galhas radiculares, pertencentes ao gênero Meloidogyne, constituem o grupo de fitonematóides com maior importância econômica na agricultura. Sua ampla distribuição mundial, o grande número de hospedeiros existentes e a interação com outros organismos patogênicos colocam-nos entre os primeiros patógenos responsáveis pela limitação da produtividade agrícola mundial (SASSER, 1980; SASSER e CARTER, 1985).

O algodão é uma cultura economicamente importante no Brasil, sendo São Paulo, Paraná e Minas Gerais os estados de maior produtividade algodoeira (GRIDI-PAPp et al., 1992). Como os nematóides têm sido um sério problema na cultura do algodão, há grande interesse em melhorar geneticamente as cultivares, tornando-as mais resistentes à infecção por esses parasitas. SHEPHERD e HUCK (1989) demonstraram que a infecção de $M$. incognita nas raízes de algodão resulta em ruptura da epiderme, do xilema e do tecido cortical, em resposta ao desenvolvimento das células gigantes e à formação de galhas. Vários são os efeitos de nematóides na fisiologia das plantas, devido à formação de galhas. O aumento da atividade metabólica das células gigantes estimula a mobilização de fotoassimilados da parte aérea para as raízes e, em particular, para as próprias células gigantes, nas quais são utilizados para a alimentação do nematóide (CARNEIRO, 2000).

ZIMMERMAN e McDoNOUGH (1978) constataram que nematóides causam mudanças anatômicas nas raízes, ocasionando alteração na absorção de água e, conseqüentemente, na absorção de nutrientes. Pode ocorrer, também, redução na absorção de nutrientes pela própria redução do sistema radicular infectado e por disfunções nele ocasionadas (HUNTER, 1958; HUSSEY, 1985).

$\mathrm{O}$ nutriente mineral necessário às plantas em maior quantidade é o nitrogênio, cuja limitação di- minui a taxa de divisão celular, a expansão celular, a fotossíntese, entre outros efeitos (EvANs, 1983; SINCLAIR e HoRIE, 1989). Apesar da provável queda na absorção de nitrogênio em plantas atacadas por nematóides, Hunter (1958) observou que folhas cloróticas em plantas de tomate infectadas por $M$. incognita raça 1 apresentaram conteúdo normal de N, P, Ca, Mg e Fe. $\mathrm{O}$ conteúdo de $\mathrm{Cu}$ não foi afetado. Dropkin e KING (1956) e BERGERSON (1966) não detectaram alteração no transporte de $\mathrm{N}$ e $\mathrm{K}$ em plantas de tomate infectadas por M. incognita.

No que se refere à fotossíntese, LOVEYs e BIRD (1973) constataram que alto grau de infecção por $M$. javanica, em tomate, causou um declínio na taxa fotossintética líquida, dois dias após a inoculação. Alto grau de infecção pelo nematóide Globodera pallida diminuiu a fotossíntese e a transpiração de batata (SCHANs, 1991).

Além dos trabalhos citados acima, assim como em outros (Siddiqui e MaHAmood, 1994; KoenNing e BarKER, 1995), a quantidade de inóculo usada, seja na forma de ovos ou juvenis de segundo estágio (J2), é muito maior que a utilizada normalmente para avaliar a resistência de plantas, tendo atingido, em alguns estudos, até mais de 300.000 J2 por planta. Dessa forma, alterações na fisiologia das plantas são observadas pouco dias após a inoculação. Para programas de melhoramento de algodão, são utilizados normalmente 2.000 a 3.000 ovos por planta ${ }^{(5)}$. Um outro exemplo: na avaliação da resistência a Meloidogyne exigua de progênies derivadas de hibridações entre cafeeiros das espécies Coffea arabica e C. canephora, Silvarolla et al. (1998) inocularam nas plantas 2.000 e 5.000 ovos. Isso se deve ao fato de que, para fins comparativos, na avaliação do sucesso do nematóide em infectar uma planta, leva-se em consideração o número inicial e o final de ovos ou J2; assim, um

(5) CIA, E. Instituto Agronômico, Campinas (SP), comunicação pessoal. 
inóculo com número elevado de ovos ou 22 pode levar à subestimação do índice de sucesso. Por exemplo, para canola, apesar da expressiva redução no crescimento de plantas que receberam 12.500 ovos de M. incognita e $M$. javanica, o índice de galhas foi igual ao de plantas que receberam 2.500 ovos (FerRaz e Rossi, 1999).

O presente trabalho teve por objetivo estudar algumas alterações de ordem fisiológica e bioquímica em cultivares de algodão, moderadamente resistentes e suscetíveis, infectadas com $M$. incognita raça 3, com doses de inóculo de 500 e 5.000 ovos.

\section{MATERIAL E MÉTODOS}

Foram utilizadas duas cultivares de algodão, contrastantes quanto à resistência ao nematóide M. incognita raça 3. Sementes da cultivar Acala, suscetível ao referido nematóide, foram obtidas junto ao Centro Nacional de Pesquisa do Algodão - Embrapa, em Campina Grande (PB). Sementes da cultivar IAC-20, com caracteristíca de resistência, foram obtidas no Centro de Algodão do Instituto Agronômico de Campinas (SP).

Como substrato foi utilizada uma mistura de solo/areia na proporção de 1:1, esterilizada por fumigação com brometo de metila $\left(150 \mathrm{~cm}^{3} \cdot \mathrm{m}^{-3}\right)$. As extrações de ovos para as inoculações foram feitas de acordo com SASSER et al. (1984); as concentrações de ovos desejadas em determinado volume de água foram obtidas por meio de diluições.

Sementes de cada cultivar foram colocadas para germinar em copos plásticos de $500 \mathrm{~cm}^{3}$ contendo a mistura estéril de solo e areia. Para uniformização das plantas, três sementes foram colocadas em cada copo, sendo, posteriormente, selecionada apenas uma plântula. Após a emergência da segunda folha, 14 vasos receberam suspensão de $3 \mathrm{~mL}$ contendo 500 ovos de M. incognita raça 3,14 receberam suspensão de $3 \mathrm{~mL}$ contendo 5.000 ovos, e outros 14 vasos foram considerados testemunhas. Todas as plantas foram irrigadas, uma vez por semana, com $80 \mathrm{~mL}$ de solução nutritiva de HoAgland e ARNon (1950).

Aos 90 dias após a inoculação selecionaram-se, ao acaso, sete vasos de cada tratamento para a realização de diversas medidas. As de fotossíntese foram realizadas na terceira folha, utilizando-se um analisador de gás carbônico por infra-vermelho (LICOR, modelo LI-6200), sendo tomadas entre $9 \mathrm{~h}$ e $10 \mathrm{~h}$ da manhã de um dia de pleno sol. Após a medição da fotossíntese retiraram-se 15 discos (6 $\mathrm{mm}$ de diâmetro) da primeira, segunda e terceira folhas, a partir do ápice, sendo 5 de cada folha, e colocados em frascos contendo $10 \mathrm{~mL}$ de uma solução de metanol, clorofórmio e água, na proporção de 12:5:3 (v/v/v) (BIELESK e TURNER, 1966). Na retirada dos discos evitaram-se as nervuras mais grossas. Esses frascos permaneceram por uma semana a $4{ }^{\circ} \mathrm{C}$, até a completa descoloração dos tecidos. Posteriormente retirou-se $1 \mathrm{~mL}$ da solução para a dosagem de clorofilas (LichtentHALER e WelLbURN, 1983), e ao restante foram adicionados 3,4 mL de água e 2,3 mL de clorofórmio, agitando-se vigorosamente para boa homogeneização. Os frascos permaneceram durante um dia a $4{ }^{\circ} \mathrm{C}$ para a separação de fases, recuperando-se a fase superior (aquosa-metanólica), na qual foi feita a determinação de açúcares solúveis (Dubors et al., 1956), utilizando-se sacarose como referência. A atividade da redutase do nitrato foi determinada in vivo (RADIN, 1974), sendo feita em discos foliares de $6 \mathrm{~mm}$ de diâmetro, também retirados da segunda folha. Nessas mesmas plantas determinaram-se as alturas, e as raízes foram removidas do substrato, lavadas em água corrente e pesadas. Em seguida foram trituradas em liquidificador com solução de hipoclorito de sódio 1\%, passadas em peneira de 60 malhas para retenção dos resíduos, e os ovos, recolhidos em peneira de 500 malhas, para avaliação da quantidade (HUSSEY e BARKER, 1973). O número de ovos foi estimado por contagem em câmara de Peters, sob microscópio óptico. Foram determinados, então, o número de ovos por massa fresca de raízes e o fator de reprodução, resultante da divisão do número de ovos extraídos pelo número de ovos inoculados. Os resíduos das raízes trituradas e recuperados da peneira de 60 malhas foram secos em estufa a $70{ }^{\circ} \mathrm{C}$, durante uma semana, e a massa seca determinada. As folhas de cada planta foram coletadas separadamente e também secas em estufa.

As sete plantas restantes de cada dose de inóculo, não utilizadas nas análises bioquímicas, foram submetidas à deficiência hídrica, irrigadas até a capacidade de campo e, após total escorrimento do excesso de água, determinaram-se as massas dos vasos. A partir de então, os vasos passaram a ser pesados diariamente e irrigados com $50 \%$ da massa perdida entre um dia e outro $(1 \mathrm{~mL}=1 \mathrm{~g})$. Dessa forma permitiu-se o estabelecimento de uma deficiência hídrica gradual, estendedo-se até oito dias do início da interrupção da rega. Ao final foi determinado o potencial da água da terceira folha usando-se uma bomba de pressão (Plant Moisture Stress-PMS Instruments Co. Modelo 102).

\section{RESULTADOS E DISCUSSÃO}

O número de ovos por grama de raiz, para plantas de 'Acala' que receberam 500 e 5.000 ovos, foi $253 \pm 32$ e $377 \pm 27$, respectivamente, e para 'IAC-20', 
$0,60 \pm 0,15$ e 1,70 $\pm 0,49$. Os fatores de reprodução em 'Acala' foram 3,30 $\pm 0,18$ e 3,80 $\pm 0,02$, e, em 'IAC-20', $0,60 \pm 0,11$ e 1,7 $\pm 0,04$, para 500 e 5.000 ovos respectivamente. Portanto, a cultivar Acala pode ser considerada bastante suscetível e 'IAC-20' moderadamente resistente, pois, segundo TAYLOR e SASSER (1978), fatores de reprodução maiores que um indicam plantas suscetíveis, menores que um, resistentes, e próximos ou igual a um, plantas moderadamente resistentes ou moderadamente suscetíveis.

Em relação aos parâmetros altura (Figura 1A) e massa seca de folhas (Figura 1B), houve sempre a tendência de maiores valores no tratamento com 500 ovos. Entre as cultivares os valores observados foram semelhantes, porém, para a matéria seca de raiz, além de haver aumento com o aumento do inóculo, 'Acala' apresentou sempre maior massa (Figura 1C). É provável que o aumento na parte aérea tenha ocorrido como uma resposta das plantas ao estresse moderado causado pelo nematóide. Por outro lado, na mesma cultivar observou-se o maior aumento na matéria seca do sistema radicular. O aumento de massa de raízes infectadas por nematóides tem sido discutido por alguns autores, sugerindo que isso seria a conseqüência de efeito combinado da emissão de novas raízes secundárias, nos locais de infecção do nematóide (HUTANGURA et al., 1999) e formação de galhas (CARNEIRO, 2000; CARNEIRO et al., 1999).

A murcha é normalmente indicada como um dos sintomas do ataque de nematóides em plantas, decorrente de mudanças anatômicas que poderiam alterar a absorção e o transporte de água, afetando todo o estado hídrico da planta (DorHout et al., 1993; Wilcox-LeE e LoRIA, 1987). Entretanto, no presente trabalho, após as plantas terem sido submetidas ao estresse hídrico, o potencial da água aumentou para 'Acala', com o aumento na dose de inóculo (Figura 2A). Por outro lado, pouca alteração ocorreu com o potencial da água de 'IAC-20'. O aumento na cultivar suscetível poderia ser explicado pelo maior sistema radicular, que foi de $52 \%$ nas plantas que receberam 5.000 ovos. Apesar de necessitar verificação, uma vez que nematóides podem causar obstrução do xilema e, portanto, do transporte de água, é possível que o maior potencial da água observado nas plantas de 'Acala' seja devido à emissão de novas raízes secundárias. Por sua vez, a massa de raízes se manteve constante nas plantas de 'IAC-20' que receberam nematóides, não diferindo do controle porque provavelmente não emitiram raízes secundárias e, portanto, tendo limitação quanto à água disponível.

$\mathrm{O}$ teor de clorofila tendeu a aumentar com o aumento do nível de inóculo, sendo tal fato mais evi-


Figura 1. Altura (A), massa seca de folhas (B) e massa seca de raiz $(C)$ em plantas das cultivares de algodão Acala e IAC-20 inoculadas com 0, 500 e 5.000 ovos de M. incognita raça 3. Médias de sete repetições e as barras sobre as colunas indicam os erros-padrão.

dente em 'Acala' (Figura 2B). Aumento de fotossíntese também foi observado em ambas as cultivares (Figura 2C), com exceção da cultivar Acala, que recebeu 5.000 ovos, refletindo-se em uma tendência de 
elevação no teor de açúcares solúveis (Figura 2D). A atividade de redutase de nitrato intensificou-se apenas em 5.000 ovos de inóculo (Figura 2E).

A elevação da taxa fotossintética, com a ampliação da dose de inóculo, pode ser decorrente do aumento de algum dreno metabólico nas plantas infectadas. A partir da constatação de que com 5.000 ovos houve redução da matéria seca da parte aérea e aumento no sistema radicular em 'Acala', pode-se especular que: a elevação da taxa fotossintética nessa dose de inóculo deveu-se à emissão de novas raízes secundárias e/ou formação de galhas, e que, ao mesmo tempo, houve mudança no padrão de distribuição de fotoassimi-
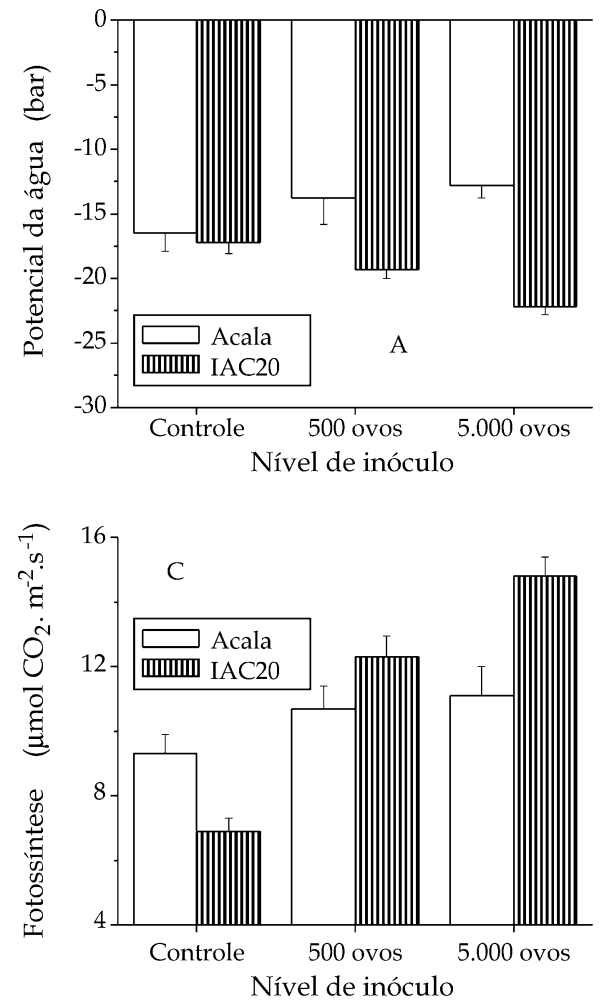

lados, sendo estes direcionados mais intensamente para as raízes.

A variedade IAC-20, entretanto, tida como moderamente resistente, apresentou grande incremento da fotossíntese, superior à 'Acala', não tendo, contudo, alterada a matéria seca de raízes. Esse aumento poderia estar relacionado ao gasto energético da planta no desencadeamento dos mecanismos de resistência (McLaughlin e Shriner, 1978). Melakeberhan e Ferris (1988) observaram que os poucos nematóides ( $M$. incognita) que se estabeleceram nas raízes de uma cultivar de uva, moderadamente resistente, desenvolveram-se tão bem quanto na cultivar suscetível.
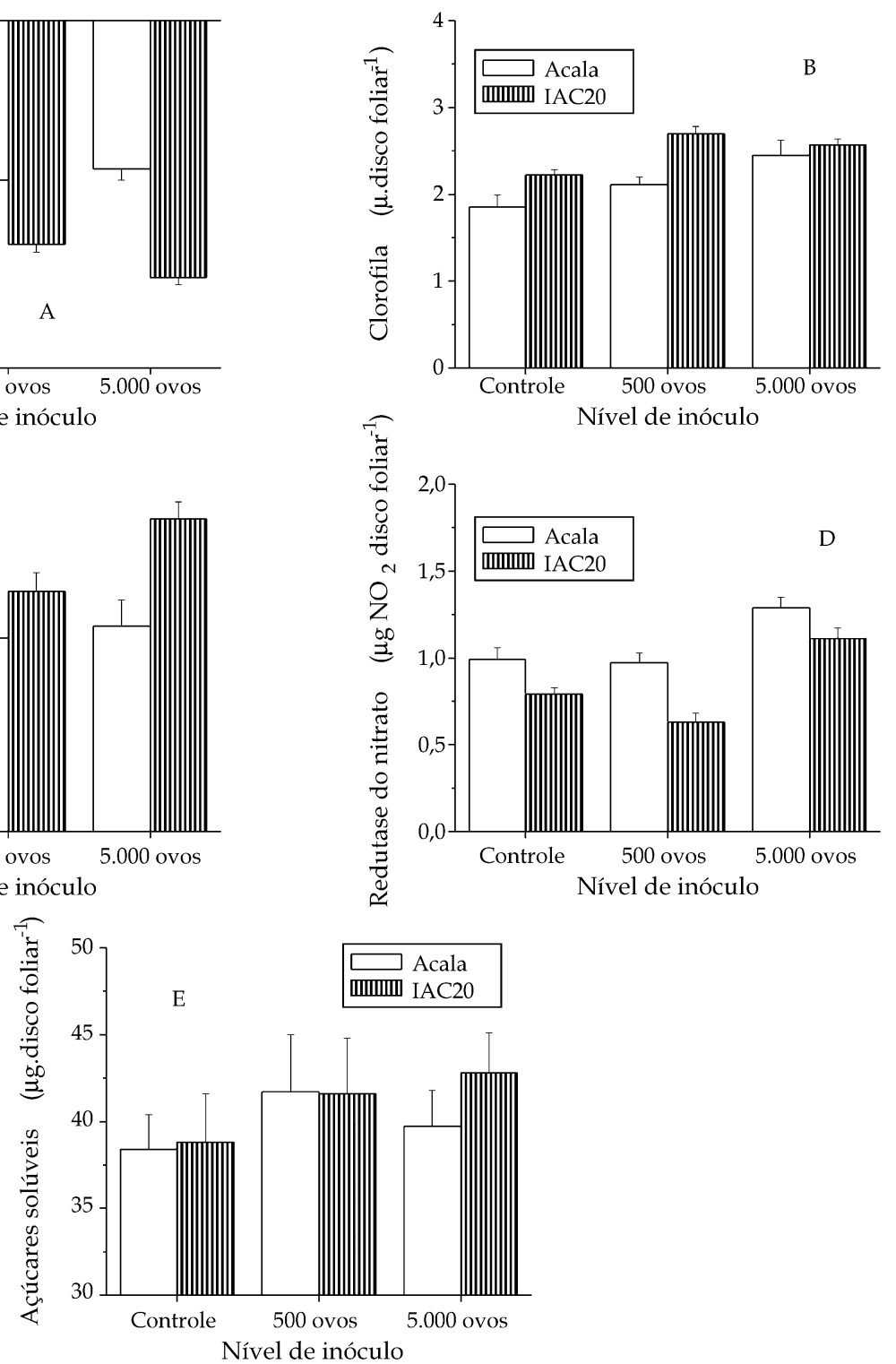

Figura 2. Potencial da água (A), teor de clorofila (B), atividade fotossintética (C), atividade da enzima redutase do nitrato (D) e teor de açúcares solúveis (E) nas folhas de plantas das cultivares de algodão Acala e IAC20 inoculadas com 0, 500 e 5.000 ovos de M. incognita raça 3. Médias de sete repetições e as barras sobre as colunas indicam os erros-padrão. 
Isso levou MELAKEBERHAN et al. (1990) a especularem que cultivares resistentes e suscetíveis poderiam consumir sua energia diferentemente, seja para defenderse contra a infecção e reprodução do nematóide, seja para reparar os danos causados pela infecção. Assim, esses autores conduziram ensaios nos quais notaram que a energia consumida por nematóides representou grande parte da energia consumida pela planta, tanto na cultivar de uva tolerante como na suscetível. Embora tendo observado maior dano na cultivar suscetível, os resultados obtidos levaram os autores a concluir que também existe gasto considerável de energia na cultivar tolerante, em conseqüência do processo de defesa e reparo.

A tendência de aumento da atividade da redutase do nitrato e de clorofila é concordante com o aumento da fotossíntese, pois a incorporação de nitrogênio em aminoácido é dependente da disponibilidade de estruturas de carbono (açúcares produzidos na fotossíntese). Entretanto, o conteúdo de carboidratos solúveis aumentou em 'IAC-20' com 500 e 5.000 ovos, não ocorrendo o mesmo com 'Acala', para a qual houve elevação somente com 500 ovos. O baixo valor em 'Acala' que recebeu 5.000 ovos seria resultado da distribuição preferencial para as raízes, como sugerido acima. Partição de carbono em favor das raízes foi observada em soja infectada com $M$. incognita e M. javanica (CARNEIRO et al., 1999).

Vários trabalhos citam redução da fotossíntese após a inoculação de grande número de nematóides. Isso foi observado por LovEYs e BIRD (1973) em tomateiros infectados com 30.000 a 50.000 J2 de M. javanica. SCHANS (1991) aplicou em duas cultivares de batata, uma suscetível e outra resistente, 60.000 e $260.000 \mathrm{~J} 2$ de Globodera pallida, respectivamente, e observou redução da fotossíntese líquida em ambas as cultivares, em apenas três dias após a inoculação. KoENNING e BARKER (1995) aplicaram, em soja, gradações de 80.000 a 350.000 J2 de Heterodera glycines, sob diferentes condições de cultivo, e verificaram que a variação da fotossíntese foi pouco significativa. Segundo esses autores, apenas parte da redução na produção de grãos poderia ser atribuída à restrição da fotossíntese causada pelo nematóide. Por outro lado, utilizando doses bem menores de inóculo (2.000 a $4.000 \mathrm{~J} 2$ ), outros autores também observaram redução de fotossíntese, clorofila ou atividade da redutase de nitrato (WALLACE, 1974; MELAKEBERHAM et al., 1985; HASEEB et al., 1990; SIDDIQUI e MAHAMOOD, 1994).

Assim, torna-se claro que o tipo e a dose do inóculo (ovos e pouco inóculo respectivamente) diferenciam o presente trabalho de outros da literatura (J2 e muito inóculo). Deve-se considerar também que a utilização de ovos não garante homogeneidade de infecção, co- mo é o caso de J2, uma vez que podem estar em diferentes estágios de desenvolvimento e, portanto, com a eclosão ocorrendo em momentos distintos. Tal fato teve possivelmente grande influência nos resultados obtidos nesta pesquisa. Assim, esses resultados representam, aparentemente, a ocorrência de um estresse devido ao pequeno número de fêmeas instaladas. De certa forma, a pouca infecção poderia ter levado a um estímulo semelhante àquele causado por frutos na fotossíntese de plantas, ou seja, à indução de maior produção de fotoassimilados em resposta à maior demanda (SONNEWALD e Willmitzer, 1992). O significante papel de nematóides como drenos de fotoassimilados foi demonstrado por DunCAN e EISSENSTAT (1993). Em laranjeiras infectadas com Tylenchulus semipenetrans, que tiveram os frutos removidos, houve favorecimento da multiplicação do nematóide nas raízes; o inverso, ou seja, a manutenção de frutos, reduziu sua população.

Além do tipo e da quantidade de inóculo, outro fator a se considerar é o tempo decorrido entre a inoculação e a avaliação. Nesse sentido, em plantas que receberam pouco inóculo e avaliadas após muitos dias, as alterações seriam reflexo de mais de um ciclo do nematóide, portanto, de número supostamente maior de fêmeas infectando as raízes. A priori, isso talvez correspondesse à inoculação com altas doses de inóculo e à avaliação em um curto período. Porém, há de se considerar que, no primeiro caso, vários outros processos podem ocorrer até a avaliação do material, mas, principalmente, a oportunidade de infecção secundária por microrganismos. A vantagem do segundo caso, no entanto, consiste na possibilidade de se restringirem as avaliações ao período de, aproximadamente, um ciclo ou fases de um ciclo. Não há dúvida, porém, de que o primeiro caso é mais comum de ocorrer.

\section{CONCLUSÕES}

As respostas fisiológicas observadas em plantas que receberam poucos ovos de nematóide são bastante diversas das observadas em estudos com altas doses e com uso de J2. Assim, tais dados não seriam comparáveis, no que diz respeito à fisiologia de plantas infectadas. Apesar de várias afirmações sobre os efeitos de nematóides em plantas, poucos ainda são os estudos fisiológicos abrangendo situações reais, ou seja, o acompanhamento de plantas infectadas em condições de campo, desde o plantio até a colheita, concomitantemente ao acompanhamento do desenvolvimento do nematóide nas raízes das plantas. Informações dessa natureza poderiam fornecer maiores 
subsídios para o manejo de nematóides, assim como para a condução de culturas.

\section{REFERÊNCIAS BIBLIOGRÁFICAS}

BERGERSON, G.B. Mobilization of minerals to the infection site of root-knot nematodes. Phytopathology, St. Paul, v.56, p.1287-1289, 1966.

BIELESK, R.L.; TURNER, N.A. Separation and estimation of amino acids in crude plant extracts by thin layer electrophoresis and chromatography. Analytical Biochemistry, Duluth, v.17, p.278-282, 1966.

CARNEIRO, R.G. Efeitos de Meloidogyne incognita raça 3 e M. javanica sobre a absorção e translocação de nitrogênio, fósforo e cálcio e sobre a partição de carbono em cultivares de soja. Piracicaba, 2000. 96p. Tese (Doutorado em Fitopatologia) - ESALQ/Universidade de São Paulo.

CARNEIRO, R.G.; FERRAZ, L.C.C.B.; MAZZAFERA, P. Carbon partitioning in soybean infected with Meloidogyne incognita and M. javanica. Journal of Nematology, Lake Alfred, v.31, p.348-355, 1999.

DORHOUT, R.; GOMMERS, F.J.; KOLLOFFEL, C. Phloem transport of carboxyfluorescein through tomato roots infected with Meloidogyne incognita. Physiological and Molecular Plant Pathology, New York, v.43, p.1-10, 1993.

DROPKIN, V.H.; KING, R.C. Studies on plant parasitic nematodes homogeneously labeled with radiophosphorus. Experimental Parasitology, Duluth, v.5, p.269480, 1956.

DUBOIS, M.; GILLES, K.A.; HAMILTON, J.K.; REBERS, P.A.; SMITH, F. Colorimetric method for determination of sugars and related substances. Analytical Chemistry, Washington, D.C., v.28, p.350-356, 1956.

DUNCAN, L.W.; EISSENSTAT, D.M. Responses of Tylenchulus semipenetrans to citrus fruit removal: implications for carbohydrate competition. Journal of Nematology, Lake Alfred, v.25, p.7-14, 1993.

EVANS, J.R. Nitrogen and photosynthesis in flag leaf of wheat (Triticum aestivum L.). Plant Physiology, Rockville, v.72, p.297-302, 1983.

FERRAZ, L.C.B.; ROSSI, C.E. Patogenicidade de Meloidogyne incognita raça 2 e $M$. javanica (Nemata: Tylenchoidea) a cultivares de canola. Revista de Agricultura, Piracicaba, v.74, p.317-324, 1999.

GRIDI-PAPP, I.L.; CIA, E.; FUZATTO, M.G.; SILVA, N.M.; FERRAZ, C.A.M.; CARVALHO, N.; SABINO, N.P.; KONDO, J.I.; PASSOS, S.M.G.; CHIAVEGATO, E.J.; CAMARGO, P.P.;CAVALERI,P.A. Manual do produtor de algodão. São Paulo, Bolsa de Mercadorias \& Futuros, 1992. 158p.

HASEEB, A.; SRIVASTAVA, N.K.; PANDEY, R. The influence of Meloidogyne incognita on growth, phisiology, nutrient concentration and alkaloid yield of Hyoscya- mus Niger . Nematologia Mediterranea, Bari, v.18, p.127$129,1990$.

HOAGLAND, D.R.; ARNON, D.I. The water culture method for growing plants without soil. Davis: California Agricultural Experiment Station, 1950. 34p. (Circular, 347).

HUNTER, A.H. Nutrient absorption and translocation of phosphorus as influenced by the root-knot nematode Meloidogyne incognita e M. acrita. Soil Science, Baltimore, v.86, p.245-250, 1958.

HUSSEY, R.S. Host-parasite relationships and associated physiological changes. In: SASSER, J.N.; CARTER, C.C. (Eds.). An advanced treatise on Meloidogyne: biology and control. Raleigh: North Carolina State University, 1985. p.143-153.

HUSSEY, R.S.; BARKER, K.R. A comparison of methods of collecting inocula of Meloidogyne spp., including a new technique. Plant Disease Reporter, St. Paul, v.57, p.10251028, 1973.

HUTANGURA, P.; MATHESIUS, U.; JONES, M.G.K.; ROLFE B.G. Auxin induction is a trigger for root gall formation caused by root-knot nematodes in white clover and is associated with the activation of the flavonoid pathway. Australian Journal of Plant Physiology, Melbourne, v.26, p.221-231, 1999.

KOENNING, S.R.; BARKER, K.R. Soybean photosynthesis and yield as ifluenced by Heterodera glycines, soil type and irrigation. Journal of Nematology, Lake Alfred, v.27, p.51-62, 1995.

LICHTENTHALER, H.K.; WELLBURN, A.R. Determination of total carotenoids and chlorophylls $a$ and $b$ of leaf extracts in different solvents. Biochemical Society Transactions, London, v.11, p. 591592, 1983.

LOVEYS, B.R.; BIRD, A.F. The influence of nematodes on photosynthesis in tomato plants. Physiological Plant Pathology, New York, v.3, p.525-529, 1973.

McLAUGHLIN, S.B.; SHRINER, D.S. Allocation of resources to defense and repair. In: Horsfall, J.G.; Cowling, E.B. (Eds.). Plant disease: an advanced treatise. New York, Academic Press, 1978. vol. 5, p.407-431.

MELAKEBERHAN, H.; WEBSTER, J.M.; BROOKE, R.C. Response of Phaseolus vulgaris to a single generation of Meloidogyne incognita. Nematologica, Leiden, v.31, p.190-202, 1985.

MELAKEBERHAN, H.; FERRIS, H. Growth and energy demand of Meloidogyne incognita on susceptible and resistant Vitis vinifera cultivars. Journal of Nematology, Lake Alfred, v.20, p.545-554, 1988.

MELAKEBERHAN, H.; FERRIS, H.; DIAS, J.M. Physiological response of resistant and susceptible Vitis vinifera to Meloidogyne incognita. Journal of Nematology, Lake Alfred, v.22, p.224-230, 1990. 
RADIN, J.W. Distribution and development of nitrate reductase activity in germinating cotton seedlings. Plant Physiology, Rockville, v.40, p.69-71, 1974.

SASSER, J.N. Root-knot nematodes a global menace to crops production. Plant Disease, St. Paul, v.64, p.36-41, 1980.

SASSER, J.N.; CARTER, C.C. Overview of the international Meloidogyne project (1975-1984). In: Sasser, J.N.; Carter, C.C. (eds.). An Advanced Treatise on Meloidogyne: Biology and Control. Raleigh: North Carolina State University Graphics, 1985. v.1, p.19-24.

SASSER, J.N.; CARTER, C.C.; HARTMAN, K.M. Standardization of host suitability studies and reporting of resistance to root-knot nematodes. Raleigh: North Carolina State University Graphics, 1984. 7p.

SCHANS, J. Reduction of leaf photosynthesis and transpiration rates of potato plants by second-stage juveniles of Globodera pallida. Plant Cell and Environment, Oxford, v.14, p.707-712, 1991.

SHEPHERD, R.L.; HUCK, M.G. Progression of root-knot nematode symptoms and infection on resistant and susceptible cotton. Journal of Nematology, Lake Alfred, v.21, p.235-241, 1989.

SIDDIQUI, Z.A.; MAHAMOOD, I. Effects of Heterodera cajani on growth, chlorophyl content and activity of some enzymes in Feijão guandu. Nematropica,Auburn, v.24, p.103-111, 1994.
SILVAROLLA, M.B.; GONÇALVES, W.; LIMA, M.M.A. Resistência de cafeeiro a nematóides: V. Reprodução de Meloidogyne exigua em cafeeiros derivados da hibridação de Coffea arabica com C. canephora. Nematologia Brasileira, Piracicaba, v.22, p.51-59, 1998.

SINCLAIR, T.R.; HORIE, T. Leaf nitrogen, photosynthesis, and crop radiation use efficiency: a review. Crop Science, Madison, v.29, p.90-98, 1989.

SONNEWALD, U.; WILLMITZER, L. Molecular approaches to sink-source interactions. Plant Physiology, Rockville, v.99, p.1267-1270, 1992.

TAYLOR, A.L.; SASSER, J.N. Biology identification and control of root-knot nematodes (Meloidogyne species). Raleigh: North Carolina State University Graphics, 1978. 111p.

WALLACE, H.R. The influence of root-knot nematode, Meloidogyne javanica, on photosynthesis and on nutrient demand by roots of tomato plants. Nematologica, Leiden, v.20, p.27-33, 1974.

WILCOX-LEE, D.A.; LORIA, R. Effects of nematode parasitism on plant-water relations. In: Veech J. A.; Dickison D. W. (Eds.). Vistas on nematology. Hyatsville: Society of Nematologists, 1987. p.260-266.

ZIMMERMAN, M.H.; McDONOUGH, J. Disfunction in the flow of food. In: Horsfall, J.G.; Cowling, E.B. (Eds.). Plant disease: an advanced treatise. New York: Academic Press, 1978. v.3, p.117-140. 